\title{
Quantifying Bio-Engineering: The Importance of Biophysics in Biofuel Research
}

\author{
Patanjali Varanasi ${ }^{1,2,3}$, Lan Sun ${ }^{1,2,3}$, Bernhard Knierim ${ }^{1,2}$, Elena Bosneaga ${ }^{2,4}$, \\ Purbasha Sarkar2,4, Seema Singh ${ }^{1,3}$ and Manfred Auer ${ }^{1,2,4}$ \\ ${ }^{1}$ Joint BioEnergy Institute, Physical Biosciences Division \\ Lawrence Berkeley National Laboratory, Emeryville, CA \\ ${ }^{2}$ Life Sciences Division, Lawrence Berkeley National Laboratory, Berkeley, CA \\ ${ }^{3}$ Sandia National Laboratories, Biomass Science and \\ Conversion Technology Department, Livermore, CA \\ ${ }^{4}$ Energy Biosciences Institute, UC Berkeley, CA \\ United States
}

\section{Introduction}

The decreasing availability and the increasing demand for fossil energy sources as well as concerns of irreversible climate change have sparked a quest for alternative energy sources, including carbon-neutral transportation fuels. One such alternative to fossil fuels is biofuel produced from currently unused plant biomass. Since lignocellulosic biomass -unlike cornstarch- cannot be used as a food source for humans it constitutes an ideal source for the production of biofuels. Currently, the production of biofuels from this unutilized biomass is not economically viable and crippled due to high costs involved in the conversion of biomass to sugars, and the limited repertoire of current generation microbes to produce a host of necessary transportation fuels beyond the simple fermentation into ethanol. Recently extensive research efforts are underway to overcome the bottlenecks for an economically viable lignocellulose biofuel industry. Advances must be made in the area of feedstocks engineering, optimization of deconstruction processes, including chemical, enzymatic or microbial pretreatment and saccharification approaches, as well as in the area of fuels synthesis, and require a variety of biophysical approaches, some of which are discussed here in more detail.

\section{ThermoGravimetric Analysis (TGA) and Differential Scanning Calorimetry (DSC)}

Thermogravimetric analysis is a thermoanalytical technique that measures the change in mass of a substrate as a function of temperature. The temperature of the sample and a blank are increased/decreased at a constant rate and the change in weight is measured as a function of sample temperature. As these experiments are highly temperature sensitive they are conducted in highly insulated chambers. The sample holders used in TGA experiments have to be highly conducting to avoid any lag between temperature measured outside and 
inside the sample holder. There is practically no sample preparation required and the technique can be used for solids or liquids or a mixture of both. A small mass of the sample $(<10 \mathrm{mg})$ is weighed and its mass change is measured against the mass change of an empty sample holder. The sample holders come with and without a hole in the lid thus allowing (or not) the flow of gases. The TGA experiments may be conducted under either inert (Nitrogen or Argon) or under oxidative conditions (Oxygen or Air). The decrease or increase in weight of the sample as the temperature is increased may indicate the loss of the material due to vaporization, decomposition or oxidation. The weight loss curve generated by the TGA instrument is representative of this mass loss (or increases) as a function of temperature changes. A derivative of the weight loss curves is usually used to easily read the TGA curves. The differential thermogravimetric (dTG) curves are useful for finding the temperature of vaporization or decomposition of both pure compounds and mixtures. TGA curves taken under different temperature ramp rates are used to find the order and activation energies of the decomposition reactions. TGA curves may also be used to find the total moisture content of the samples based on the weight loss in the region where water evaporates $\left(80^{\circ} \mathrm{C}\right.$ to $\left.120^{\circ} \mathrm{C}\right)$. TGA/DSC techniques are particularly useful for mixtures with different constituents. Based on the temperature at which each of the constituents decompose or vaporize we may define weight loss region for each of the constituents. We may then use weight percent loss in each region to find the composition changes of the individual constituents in the original sample.

Differential scanning calorimetry (DSC) is also a thermoanalytical technique and is often used in conjunction with TGA. It measures the energy required to increase or decrease the sample temperature against a blank. Like TGA this technique also requires minimum sample preparation and can be used for solid, liquids or a mixture of both. Similar sample holders and similar sample weights are used in DSC as in TGA. Experimental conditions like, temperature ramp rate and gaseous atmosphere can be changed based on the kind of analysis. A DSC cure is highly data-rich as it gives us crucial information such as enthalpy of melting, boiling, decomposition and oxidation. By comparing both TGA and DSC curves one can determine the temperature at which the system boils, decomposes or oxidizes. An endothermic mass loss can be attributed to boiling or endothermic decomposition. An exothermic mass change is usually due to exothermic decomposition or oxidation of the substrate. Thus, DSC data is also used to find the caloric value of the decomposition and oxidation reactions. DSC data is used to find the endothermic energy required for dehydrating a sample in the moisture loss region. Such data may be used to find if the moisture is physically absorbed to the substrate or is chemically complexed with the substrate. In case of polymer substrates, DSC curves may also be used to find the glass transition temperatures and thus degree of polymerization of the samples (DP) (Couchman 1981). Amorphous to crystalline transitions can also be determined based on the temperature of weight loss and the enthalpy of decomposition. Amorphous substrates decompose at lower temperature when compared to crystalline substrates of the same material (Kim, Eom, and Wada 2010). Amorphous materials undergo crystallization before melting. Based on ratio of the energy required for crystallization and the energy required for melting we may also find the percent crystalline material in the sample.

TGA/DSC techniques are particularly useful for biomass characterization as biomass is a complex mixture of polymers (cellulose, hemicelluloses and lignin). Serapiglia et al. (2008); Kaloustian et al. (2003); Jaffe, Collins, and Mencze (2006) have shown that the dTG curves 
from biomass can be divided into three weight loss regions for hemicelluloses followed by cellulose and lignin. TGA is a very sensitive technique and can be used to differentiate between mutants of similar kinds of feedstocks. Serapiglia et al. (2008) have used high throughput TGA to find the differences between various mutants of shrub willow. TGA was also used to find the total lignin content of various feedstocks (Ghetti et al. 1996). TGA/DSC curves were used to differentiate and understand the effects of dilute acid steam explosion on Eucalyptus (Emmel et al. 2003). They reported that lignin fragmented and recondensated during the process. A decrease in softening temperature was reported for steam exploded bamboo lignin (Shao et al. 2009), resulting in a lower molecular weight polymer. DSC was also used to differentiate between hardwoods and softwoods, based on the glass transition temperature of the lignin extracted from the woods (Kubo and Kadla 2005). Lignin decomposition by white-rot fungi was studied using DSC (Reh et al. 1987). They show that as lignin-carbohydrate bonds are broken the peaks in each region separate and become sharper. The differences between lignin carbohydrate linkages in biomass can also be found using DSC (Reh et al. 1987; Tsujiyama and Miyamori 2000). Along with these kinds of qualitative measurements, TGA and DSC can be used to calculate the enthalpy, activation energy (Flynn and Wall 1966; Paul et al. 2010) and the order of the reaction as well as the percent cellulose crystallinity of the samples.

\section{Cellulose crystallinity measurement}

Measuring the percent crystallinity of the biomass samples is particularly important as it affects rate and yield of enzymatic saccharification (Hall et al. 2010). It is challenging to measure the percent crystallinity of the biomass using DSC, as cellulose decomposes even before it undergoes melting (Paul et al. 2010; Kaloustian et al. 2003; Soares et al. 1995). As enthalpy of crystallization and enthalpy of melting are required to find the percent crystallinity of the sample, it is not possible to measure percent crystallinity of the biomass based on this technique. However, the enthalpy of dehydration of cellulose and biomass samples has been correlated to percent cellulose crystallinity of the samples based on the hydrogen bonds formed by the crystalline and amorphous cellulose. A detailed method for measuring cellulose crystallinity (CC) by DSC has been reported by Bertran and Dale (1986). They have reported that DSC provides a better way of measuring CC than other traditional approaches like XRD, especially for substance with very low crystallinity index. The amount of moisture absorbed by cellulose containing substances is dependent on the amount of crystalline and amorphous cellulose present in the substance. Amorphous cellulose absorbs a high amount of moisture while pure crystalline cellulose has no absorption capacity. Hence the endothermic dehydration peak appearing in DSC thermograms can be used to estimate the percent crystallinity of the cellulose present in the substances. Using completely amorphous cellulose measured under the same experimental conditions, the percent CC of the sample can be estimated from the following equation where $\Delta \mathrm{H}_{0}$ is the heat of dehydration for a completely amorphous cellulose sample and $\Delta \mathrm{H}_{\mathrm{s}}$ is the heat required to dehydrate the sample.

$$
\% C C=\frac{\Delta H_{0}-\Delta H_{s}}{\Delta H_{0}} \times 100
$$


In spite of the many advantages of using TGA and DSC analysis they cannot be used to find bond specific information about the substrate. Knowledge of the chemical composition of the substrate is required ahead of time. Analysis through this technique always requires one to correlate the original substrate to the pure components of the substrate. The changes to DP of a polymer can only be visualized but cannot be quantitatively correlated to changes in the molecular weight of the polymer. Also if the substrates decompose very close to each other, we cannot differentiate between the increase of one of the substrate or decrease in DP of the polymer degrading at a higher temperature. As these techniques affect the samples physically and chemically the sample used in this technique cannot be recovered or reused.

\section{Pyro-GC/MS and GC/MS}

Gas Chromatography/ Mass Spectrometry (GC/MS) is a very popular technique used to separate and identify each organic compound from mixtures. It provides both qualitative and quantitative information about the sample. Gas Chromatography (GC) separates the molecules based on their molecular weight and their volatility. Gas chromatography uses a conventional oven with a column of very small internal diameter. The temperature of the oven is changed and based on the volatility of the compounds they travel through the column at different rates. Hence they separate and reach the mass spectrometer at different times. The time a compound takes to reach the mass spectrometer from the time it is injected into the column is called retention time. The retention time of a compound depends on its molecular weight and structure (thus its volatility). The retention time of the compounds is dependent on the initial temperature and temperature ramp rate of the GC. The compounds injected into the GC reach the MS at different times based on their volatility and complex mixtures are thus separated, but this separation is not enough to understand their composition. Two compounds of different molecular weight and structure may reach the MS at the same time if they have similar volatility. A mass spectrometer is used to identify these compounds eluting from the GC column. The mass spectrometer charges the compounds, accelerates them under high magnetic fields and then breaks them into ions. Based on their mass and charge, the ions hit the detector at various positions and are thus detected. Unlike it is the case for TGA and DSC mass spectrometry analysis does not require a a thorough understanding of the mixture composition of the mixture is not necessary before analysis. However confirming the identity of the predicted compound, after the analysis of the unknown sample, with a known standard is necessary. The mass spectrometer is usually run in scan mode where it detects all the ions that hit the detector. However, scans of samples containing known compounds can be made very sensitive by forcing the mass spectrometer to detect the ions specific to the compounds of interest (selective ion mode). Based on the fragmented ions and the retention time, the chemical structure of the compound can be determined.

The mass spectrometer is very sensitive and detects even a small concentration of impurities. Hence the sample needs to be extremely pure and free of any oxygen or moisture. This implies the need for tedious sample preparation and purification step before the introduction of the sample into the instrument. It is also important to maintain the instrument itself and the column used in the GC. There is good chance of introduction of moisture and column degradation products into the sample without proper care. The quadruple of the MS itself needs to be cleaned and tested for its sensitivity frequently. 
In liquid GC/MS the samples are usually extracted into volatile organic solvents and are then injected into the GC. The compounds thus detected are biased towards non-polar organic molecules of low molecular weight. However, it is also possible to detect polar organic molecules like organic acids after derivatization thus rendering them non polar. For quantitative analysis one injects a know quantity of a compound called internal standard (IS). An internal standard is a compound, which is similar in all respects to the compounds of interest but can be separated from the original compounds in the column. Deuterated counterparts of the original compounds are usually used as internal standards for the GC/MS analysis. Internal standards are injected into the original solid or liquid prior to extraction. The compounds of interest and the original solids are then extracted into a volatile organic solvent through soxhlet extraction or liquid-liquid extraction. Specific ASTM (American Society for Testing Materials) guidelines exist for the extraction procedures for quantitative analysis of various volatile organic pollutants. A standard mixture of known quantities of the internal standard and the compound of interest is made in similar solvent. This standard mixture is then analyzed in GC/MS using the same protocol used for the sample and the standard.

Differences in efficiency of the extraction of both the compounds and the internal standard can lead to erroneous results such as incorrect concentration predictions. Only samples which contain extractible substances of lower molecular weight can be analyzed using this technique.

These shortcomings can be overcome by using pyrolysis GC-MS. In this technique, the sample is pyrolyzed at high temperatures for very short amount of time and the products thus produced are directly injected into GC/MS. This technique is usually used to find the structures of heteropolymers (polystyrene and PVC blends, lignin, etc.). The primary advantage of this technique is that it requires a small sample volume and no sample preparation, but due to measurement errors of such very small volumes pyrolysis GC-MS is difficult to quantify and inaccurate. Hence the ratio of breakdown products is often a better measurement estimate to describe the original sample.

Both GC/MS and pyrolysis GC/MS are used extensively in biofuel research. Lignin as a heteropolymer present in the biomass is often analyzed for its chemical composition using pyrolysis GC/MS (Galletti et al. 1997; Mills et al. 2009). Lignin typically contains three major constituents called $p$-hydroxyphenyl lignin (H-lignin), guaiacyl lignin (G-lignin) and syringyl-lignin (S-lignin). The structure and strength of lignin is dependent on the ratio of these three kinds of lignin (Boudet et al. 1998). Lignin rich in G-lignin is supposed to be highly condensed when compared to lignin rich in S- lignin (Chiang and Funaoka 1990). Ralph and Hatfield (1991) were one of the first ones to analyze the composition of lignin using pyrolysis GC/MS. They show that the pyrolysis products of lignin can be a variety of products derived from H, G and S-lignin. They suggest using a ratio of the total amount of $\mathrm{H}$ to the total amount of $\mathrm{G}$ to the total amount of $S$ products to find the H:G:S ratio. The S: $\mathrm{G}$ ratio of a feedstock has been shown to affect the efficiency of both the pretreatment technology and the enzymatic saccharification. Pyro-GC/MS has been used to find the changes in S:G ratio due to different pretreatments (Samuel et al. 2010; Huyen et al. 2010; Ibarra et al. 2007; Jung et al. 2010; Papatheofanous et al. 1995). The S:G ratio decreases as a result of kraft pulping (Ibarra et al. 2007) and thus hardwoods (S:G ratio >1) have always been a choice for the paper and pulp industry. Ammonia treated Miscanthus showed a decrease in the S:G ratio as result of pretreatment (Huyen et al. 2010). Samuel et al. (2010) have shown that the $S: G$ ratio of switchgrass decreased due to dilute acid pretreatment of 
biomass, showing it is easier to break S-lignin when compared to G-lignin. Based on this hypothesis genes have been identified which increase the amount S-lignin present in the plant biomass (Marita et al. 1999; Ralph 2007). The mechanism of how lignin is formed and how each gene effects the formation of these individual components of lignin has been found by both NMR and pyro-GC/MS. Pyro-GC/MS is used to differentiate between various plant mutants with different $S: G$ ratios. The changes to $S: G$ ratio as function of harvesting time has also been identified using pyro-GC/MS (Huyen et al. 2010). Feedstocks with similar lignin content have been shown to have different saccharification yields based on their S:G ratio (Davison et al. 2006). Feedstocks with higher amount S-lignin were easier to pretreat but had lower xylose yields when compared to feedstocks with higher G-lignin (Davison et al. 2006). The differences in S:G ratio has also been correlated to in-rumen digestibility of plant biomass (Guo et al. 2001; Baucher et al. 1999; Vailhé et al. 1998). As the $\mathrm{S}: \mathrm{G}$ ratio decreased the in-rumen digestibility increased, showing that feedstocks such as grass are ideal for animal feed. The lignin degradation products produced during the pretreatment process are also dependent on the $S: G$ ratio of the original lignin polymer (Chiang and Funaoka 1990). S:G ratio, as measured from pyro-GC/MS, offers a platform to correlate its effects on different biofuel production steps and thus helps us design better feedstocks.

Lignin and some of its monomers have been shown to inhibit both cellulases during enzymatic saccharification (Sewalt et al. 1997; Ximenes et al. 2010; Ximenes et al. 2011) and microbes during fuel production (Mills et al. 2009). These lignin degradation products produced during the pretreatment may have an inhibitory role on the downstream processes. These products can be identified and quantified using GC/MS (Pecina et al. 1986). Identifying these lignin degradation products is also important for the biofuel industry as it gives us an idea about the byproducts produced during the pretreatment process itself (Ehara et al. 2005). As pyro-GC/Ms can give a ratio of the amount of G-lignin and S-lignin present in the lignin, derivatization followed by the reductive cleavage (DFRC) method has been developed by Ralph et al. to measure the quantitatively the various constituents of lignin in the biomass (Lu and Ralph 1997; Lu and Ralph 1998; Lu and Ralph 1999; Peng et al.1998; Ralph and Lu 1998). This method uses GC/MS to quantify various derivatized and reduced products. Genetic pathway engineering, also known as synthetic biology, is gaining popularity as it aims to produce microbes which may in turn act as biofuel factories to produce the desired kind of fuel from the glucose units. Qualitative analysis of the composition of the fuel allows the identification of the right modification of the microbes to produce fuel. Quantification of the products is also necessary to understand the most efficient mechanism and the toxicity limit of the fuel until which the microbes can sustain. GC/MS is also used to qualitatively and quantitatively measure the fatty acids and fuels produced from the microbes ((Akiyama et al. 2008; Atsumi et al. 2008; Dai et al. 2007; Lu et al. 2008; Tang et al. 2007).

\section{Mechanical strength testing of plant stems}

As a successful feedstock will have the ability to grow tall and hence provide high yield per area of land used, it is key to measure the mechanical stability for any plant derived by breeding, mutagenesis or targeted cell wall engineering. Mechanical strength is a very important property for materials and defines the use of materials as support systems. A tensile testing instrument measures the mechanical strength, the breaking force required 
and the strain that the material underwent during the tensile test. A simple tensile testing instrument consists of a motor to apply the tensile force and a force sensor to find the tensile force applied by the motor. The approximate stress and strain during the tensile testing is calculated based on the total length and cross sectional area of the sample before the tensile testing. Tensile stress is calculated as a ratio of force to the cross-sectional area. In ductile materials, as the cross sectional area changes due to deformation under tensile stress the measurement of tensile stress using the above method gives only an approximate value for stress. As brittle materials undergo little or no deformation during tensile testing, the above method provides a better approximation for the stress in case of brittle materials. The total strain that a material underwent during tensile testing can be calculated as the ratio of the total change in length of the material to the initial length of the material. The relative brittle or ductile nature of the samples can be inferred from the total strain they undergo during tensile testing. A brittle material undergoes little deformation and shows a lower amount of strain when compared to ductile materials, which undergo a higher deformation and hence show higher amount of strain. The breaking strength of material, defined as the mechanical stress at the breaking point, is also an important property. The maximum mechanical strength and the breaking strength of a material need not be the same. During tensile testing a material elongates and reaches a maximum stress value, this is the maximum force the material can endure. The material may not break at this point, but on further increasing the strain, the material becomes weaker and breaks at a force lower than the maximum strength. This difference in behavior is also related to brittle and ductile nature of the materials. In ductile materials, like metals, the crystals lattices expand and rearrange when stress is applied, but brittle materials like ceramics are very closely packed and have no room for rearrangement when stress is applied. For the same reason, in case of brittle materials the maximum tensile strength and the breaking strength are usually the same. Tensile testing of the materials thus provides in depth knowledge about maximum mechanical strength, total strain and the nature of the material. Standard ASTM procedures have been developed for measuring the mechanical strength and the above parameters for a variety of materials (Czichos et al. 2006).

Physical pretreatment or grinding is a major part of the pretreatment that would be applied to the biomass during the production of biofuel in order to provide higher surface area, which can increase the efficiency of enzymatic saccharification ( $\mathrm{Li}$ et al. 2010) and improve the efficiency of the chemical pretreatment by providing smaller particles. Materials of lower mechanical strength are easier to handle and degrade compared to materials of higher mechanical strength. Thus the energy required during the grinding process can be co-related the mechanical strength of the biomass and this property plays an important role for biofuel production. Studies have been conducted which find the mechanical strength of the plant stems and total mechanical energy required for grinding the plant stems to be correlated. Decreasing the mechanical strength of the plant stems would in turn decrease the total energy required during the grinding process. Yu et al. (2006) studied the tensile stress and ultimate shear stress profile of switchgrass as a function of the plant maturity, the time after harvest and the moisture content. The tensile stress was reported to increase with an increase in the elapsed time after harvest and a decrease in the moisture content. Based on this they recommend tensile dominant size reduction to be carried out just after the harvest process of biomass rich in moisture. Igathinathane et al. (2008) showed the dependence of ultimate shear stress on the total moisture content of the switchgrass. 
The measurement of the mechanical strength of plant mutants has been studied to find the effect of genetic manipulations on the overall mechanical strength of the plants. An in-house instrument was developed by Prat and Paresys (1989) for measuring different mechanical strength properties of plant stems. A decreased mechanical strength may be desirable for both reduced grinding energy and easier chemical pretreatment of the feedstocks (Wilkinson and Santillana 1978; Lin et al. 1985; Grethlein and Converse 1991; Ibrahim and Pearce 1983).

Lignin present in the plant cell walls provides the plant with support. It is reported to be the most resistant to pretreatment processes (Vinzant et al. 1997; Vailhé et al. 1998; Chen and Dixon 2007). Lignin also inhibits enzymatic saccharification (Chen and Dixon 2007; Jackson et al. 2008) and microbial growth during the fuel production process (Mills et al. 2009). Hence there is a major effort by plant biologists to understand and modify lignin in plant cell wall to ease the conversion of cellulose to fuel (Himmel et al. 2007; Chen and Dixon 2007; Lee et al. 2009). In this effort, mutants are developed with modified/ lowered lignin content (Davison et al. 2006). These modifications may have a direct effect on the plant cell wall and hence on the systems that provide mechanical strength to the plant. However, the decreased mechanical strength can have an adverse effect on the growth of the plant and its ability to sustain under natural conditions. A mutagenized plant may be too weak to sustain a strong gust of wind or even a heavy downpour. This initiates the need to reach an optimum level for mechanical strength to ease the pretreatment process and not lose the ability to sustain natural calamities. Mechanical strength can also be used to find the condition under which a plant would or would not sustain under natural environmental conditions (Coops and Van der Velde 1996). An Arabidopsis mutant grown in the presence of dichlorobenzonitrile, which inhibited the production of cellulose, was also reported to have lower strength than the wild type (Ryden et al. 2003). Ethyl methanesulfonatemutagenized Arabidopsis populations showed the absence of interfascicular fibers in stems, decreased L-Fucose content and reduced mechanical strength only in the inflorescence part of the stem (Zhong et al. 1997; Reiter et al. 1993). Zhong et al. (2004) showed that the fragile fiber3 (fra3) gene of Arabidopsis thaliana, which encodes type II inositol polyphosphate 5phosphatases (5PTases), resulted in a decrease in secondary cell wall thickness and hence a reduction in stem strength. An expression of the Heynh root hair defective3 (RHD3) gene in an Arabidopsis fragile fiber4 (fra4) mutant also exhibited reduction in cell wall thickness and alteration in cell wall composition (Hu et al. 2003). This also resulted in lowered mechanical strength of the plant stems. Burk et al. (2001) isolated a group of weaker Arabidopsis plant mutants based on their mechanical strength and found a katanin-like protein, which regulated cell wall biosynthesis and cell elongation. Arabidopsis thaliana fragile fiber 8 (fra8), which was defective in xylan synthesis, was also found to have lower mechanical strength than the wild type. Arabidopsis thaliana stems down regulated in secondary cell wall-associate NAC domain protein1 (SND1) and NAC secondary wall thickening promoting factor1 (NST1) showed loss of secondary cell wall formation (Zhong et al. 2007), and as a result had lower amount of cellulose, hemicelluloses and lignin. They also showed a considerable decrease in mechanical strength. Fragile fiber (fra1) mutation of Arabidopsis exhibited a dramatic reduction in mechanical strength while no defects were found in cell wall thickness or composition or in the organization of fiber cells (Zhong et al. 2002). This lowered mechanical strength was attributed to differences in cellulose microfibril orientation in the walls of fra1. Irregular xylem8 (irx8), irxy, and irx14 mutations of Arabidopsis thaliana resulting in defects in glucuronoxylan biosynthesis (Keppler and Showalter 2010; Pena et al. 2007; Lee et al. 2010). These defects lead to decreased mechanical strength of the plant stems. An 
overexpression of these genes rescued the plants of only irx 8 and irx 9 (but not irx14) and the mechanical strength of the resulting plants was comparable to the wild type plants (Lee et al. 2010; Pena et al. 2007). A classic rice mutant brittle clum1 was shown to have reduced mechanical strength and the mutants were characterized to display increased lignin content, a reduced cell wall thickness and decreased cellulose content ( $\mathrm{Li}$ et al. 2003). The consequence of crowding on the structural behavior and response from marsh plants was studied by Harley and Bertness (1996). They reported that due to crowding the total amount of plant biomass (above the ground) decreased and resulted in thinner and weaker plants.

The effect of various gene expressions and the environmental conditions on the overall plant strength can be easily determined by mechanical strength analysis. It is also a very sensitive technique, which responds to the changes in the orientation of fibers, in plants with no changes in cell wall composition and thickness. The data from these tests would be very useful for the development of feedstock in biofuel research, which are environmentally sustainable, with desired cell wall composition and lowered grinding energies. However, this is a physical characterization technique and can be only be used to understand the effects of various parameters (like genetic modifications or natural effects) on the plant strength. It cannot be used to understand the reason for the observed increase or decrease in the mechanical strength. We are currently using this approach to swiftly characterize the mechanical properties of plants derived from a random-mutagenesis screen.

\section{Cell wall analysis by vibrational spectroscopy and microscopy}

Vibrational spectroscopy and microscopy techniques have been broadly used to analyze chemical and biological materials. The two main vibrational spectroscopic techniques, infrared spectroscopy and Raman spectroscopy, detect vibrations including both simple bond vibrations and group vibrations in molecules and thus identify these molecules by their spectral fingerprints originated from various vibrational modes. Infrared absorption typically involves photon absorption with the molecule excited to a higher vibrational energy level when the photon energy matches the energy difference between the two vibrational energy levels. This process depends on changes of dipole moments, and hence asymmetric vibrations cause the most intense infrared absorption. On the other hand, Raman scattering is the inelastic scattering of a photon that interacts with molecular vibrations, resulting in an energy shift of the exciting photon. This process depends on changes in polarizability of the electron cloud around the vibrating bonds or groups. Usually, symmetric vibrations cause the largest polarizability changes and thus render the greatest scattering. Therefore, these two techniques often provide complementary information about the molecules (Smith and Dent, 2005). All major cell wall biopolymers are both IR and Raman active. Nowadays both techniques are widely used in plant cell wall research (Dokken et al., 2005; Gierlinger and Schwanninger, 2007).

Unlike most of the current techniques for cell wall compositional analysis, such as wet chemistry assays, chromatography methods, mass spectrometry etc., which are destructive and involve breakdown of the cell wall components or extensive chemical treatment of the plant cell walls, IR and Raman spectroscopy can characterize cell wall components in their native form with minimal requirement for sample preparation. Moreover, a reliable measurement of a single sample can usually be completed from seconds to a few minutes. With the aid of a high throughput platform, such as 96-well plates, rapid screening of a large number of samples can be realized to meet the requirements of bioenergy feedstock development and biomass conversion process optimization for efficient biofuel production. 
To acquire cellular level understanding of plant cell walls, various microscopic techniques have been employed, such as bright/dark field microscopy (D'Haeze et al., 2007), polarized light microscopy (Baskin et al., 2004), transmission electron microscopy (Fromm et al., 2003), scanning electron microscopy (Persson et al., 2007b), etc. However, to localize molecules of interest, histochemical and cytochemical staining and labeling methods have to be applied (Cavalier et al., 2008; Grünwald et al., 2002; Persson et al., 2007a). Although autofluorescence of lignin can be utilized to visualize distribution of lignin in the cell wall by fluorescence microscopy (Cavalier et al., 2008; De Micco and Aronne, 2007; Singh et al., 2009), chemical information of cellulose cannot be obtained without additional techniques and quantitative analysis is difficult. On the other hand, using IR and Raman microspectroscopy, chemical maps of specific cell wall components can be generated based on their spectroscopic fingerprints without any disruption of plant tissues and necessities of staining or any other extensive treatment of the cell walls. Localized and tissue/cell specific chemical information can be revealed, which enables acquisition of chemical information on the ultrastructure of plant cell walls. Thus, IR and Raman imaging can detect important compositional changes in cell walls by mutations not necessarily reflected in their average contents and spatial chemical changes during processing, which is very difficult to achieve by other chemical analysis and microscopic methods. Between these two vibrational spectroscopic techniques, IR spectroscopy has been established for decades as a useful tool for plant cell wall research. Integrated with attenuated total reflectance (ATR) technique, synchrotron sources, focal plane array (FPA) infrared detector, and chemometric analysis, IR technique has become increasingly powerful. However, this technique is limited by low sensitivity due to non-background-free detection, low spatial resolution associated with the long infrared wavelengths, and water absorption of the infrared light (Evans and Xie, 2008). The Raman technique, on the other hand, does not have these limitations. Recent advancement in laser technology, optics and detectors has led to a rapid growth in the applications of the Raman technique. Although auto-fluorescence from lignin may sometimes interfere with Raman measurement, the use of near infrared or UV excitation or a fluorescence quencher and effective baseline correction afterwards can alleviate this problem generally. In this section, the applications of IR and Raman techniques for cell wall analysis will be discussed.

Applications of IR microspectroscopy in plant cell wall research: The most prevalent type of IR spectrometer is a Fourier Transform Infrared Spectrometer (FTIR) by recording the raw data as an interferogram and then using Fourier transform to turn this raw data into a spectrum. Attenuated total reflection (ATR) objectives containing an internal reflection element usually made of ZnSe, Ge, or diamond are often used with IR spectroscopy to study plant materials due to faster sampling, improved reproducibility and less impedance by water absorption. IR spectra are most commonly obtained from 4000 to $400 \mathrm{~cm}^{-1}$, the midinfrared region, where the peaks in the spectra can be associated with fundamental vibrations and the peak intensities are proportional to concentrations. Chemical compositions of various lignocellulosic biomass have been studied by mid-IR spectroscopy, such as wood samples, grasses and herbaceous plants (Dokken et al., 2005). Peak assignments for major cell wall components of representative biomass were summarized by Adapa et al. (2009). Compositional changes by biochemical and chemical treatments of cell walls were also investigated by FTIR. For example, behaviors of cell wall components of oak wood and barley straw treated with cellulase, acidic sodium chlorite, acid and base were studied (Stewart et al., 1995). Dilute acid pretreatment and ionic liquid pretreatment were 
compared using switchgrass as a model bioenergy feedstock (Li et al., 2010). Moreover, with the aid of chemometric techniques, FTIR can be used as a rapid method for cell wall mutant screening (Chen et al., 1998; Mouille et al., 2003). In addition, using polarizers with FTIR, the orientation of particular functional groups or cell wall components can be determined (McCann et al., 1993; Wilson et al., 2000).

The chemical imaging capability has made IR microscopy a powerful tool to reveal spatial distribution of cell wall components by collecting spectra at each spatial position in the defined area for imaging. FTIR microscopy was also demonstrated by Gierlinger et al. (2008a) to monitor in situ the enzymatic degradation of poplar wood and fast and selective degradation of the gelatinous layer in tension wood was observed. This method could be used for enzyme screening and working condition optimization for enzymes. The source intensity from conventional IR thermal sources can only provide a spatial resolution of tens of micrometers, which is limited by both signal-to-noise $(\mathrm{S} / \mathrm{N})$ ratio and diffraction, thus restricting plant analysis to the tissue level. Coupling a synchrotron IR source with a small effective source size to IR microscopy can overcome this difficulty due to the high source brightness that allows smaller regions to be probed with acceptable $\mathrm{S} / \mathrm{N}$, and thus only diffraction controls spatial resolution in this case (Carr, 1999). Using the synchrotron radiation-based FTIR microspectroscopy (SR-FTIR), imaging structures of plant tissue at cellular level with high S/N at ultraspatial resolutions $(3-10 \mu \mathrm{m})$ was achieved (Dokken and Davis, 2007; Yu et al., 2003). The main drawbacks of SR-FTIR are the expense and limited access to synchrotrons and slow imaging acquisition by the point-by-point process. A more recent technique known as focal plane array (FPA) based FTIR imaging becomes available and promises many advantages. The FPA-FTIR imaging technique is laboratory based and employs two-dimensional detector arrays to collect spectra at marked positions simultaneously. Thus, FPA-FTIR imaging can acquire the chemical map in a fraction of time required by SR-FTIR imaging. Heraud et al. (2007) compared results produced by FPAFTIR imaging and SR-FTIR imaging using Eucalyptus botryoides leaves as a model sample. They found that the two methods produced similar infrared images allowing differentiation of all tissue types in the leaves. While SR-FTIR imaging provided superior S/N ratio and better spatial resolution, it only took approximate $2 \mathrm{~min}$ for FPA-FTIR to map a $350 \mu^{2}$ of tissue area, which took approximate $8 \mathrm{~h}$ for the SR-FTIR imaging to complete.

In addition to mid-IR spectroscopy, near infrared (NIR) spectroscopy has also been used as a useful tool for compositional analysis of lignocellulosic materials. Absorption spectra in the NIR region, i.e. $14000-4000 \mathrm{~cm}^{-1}$, are derived from the overtone or harmonic vibrations. Krongtaew et al. (2010a) has summarized the NIR peak assignments for major cell wall components. Nevertheless, multivariate methods are often implemented for NIR data analysis and both qualitative and quantitative information can be derived. For example, a partial least-squares regression (PLSR) model was developed based on the NIR spectra to assess lignin composition ( $p$-hydroxyphenyl to guaiacyl ratio) in maritime pine wood (Alves et al., 2006). Key properties influencing the enzymatic hydrolysis yield and rates, such as lignin content, hemicellulose content, and cellulose crystallinity, influenced by different pretreatment methods were resolved in FT-NIR spectra and successfully evaluated by principal component analysis (Krongtaew et al., 2010a). Total residual lignin content, enzymatically released reducing sugars, total solids, volatile solids, and biogas yield can be assessed quantitatively by FT-NIR spectroscopy combined with partial least-squares regression models (Krongtaew et al., 2010b). 
Applications of Raman microspectroscopy in plant cell wall research: Classical dispersive Raman spectrometers are usually composed of laser with wavelength in the visible range for excitation, a dispersive spectrometer and a charge coupled device detector (CCD) for detection. This system is often coupled to a confocal microscope equipped with objectives with high numerical apertures to achieve high spatial resolution (Gierlinger and Schwanninger, 2007; Smith and Dent, 2005). For example, a Raman spectrometer with a $514.5 \mathrm{~nm}$ laser was used to study the concentration of lignocellulosics in the cell corner middle lamella of both birch and spruce (Tirumalai et al., 1996). However, for plant cell wall research, the strong autofluorescence from lignocellulosic materials may mask the Raman spectra. Therefore, near infrared Fourier Transform Raman spectrometers (NIR-FT Raman) with laser radiation at $1064 \mathrm{~nm}$ coupled with interferometers is often utilized for cell wall analysis, because fluorescence is much less in this region. FT-Raman was used to characterize cell wall components of milled black spruce wood (Agarwal and Ralph, 1997) and in various anatomical parts of flax (Himmelsbach and Akin, 1998). Alternatively, the excitation laser can be shifted to the UV region (below $300 \mathrm{~nm}$ ) where fluorescence is nearly absence. The utilization of UV excitation also leads to the resonance enhancement of aromatic structures and thus is very sensitive for lignin analysis. Nuopponen et al. (2004) has used UV resonance Raman (UVRR) spectroscopy to analyze the extractable compounds and solid wood samples of Scots pine. Saariaho et al. (2003) has characterized Raman peaks for $p$-hydroxyphenyl, guaiacyl and syringyl structures of lignin using UVRR. Raman peak assignments for major cell wall components were summarized by Agarwal and Ralph (1997) and Adapa et al. (2009). In addition to compositional analysis, a Raman spectroscopy-based method was also developed to obtain mechanical properties of plant cell walls (Ryden et al., 2003), which may serve as an indicator for the ease of cell wall deconstruction during pretreatment or enzymatic saccharification.

Like IR microspectroscopy, one of the major advantages of Raman technique exists in its chemical mapping capabilities. With a much higher lateral spatial resolution than IR $(\sim 1$ $\mu \mathrm{m})$, ultrastructure of plant cell walls with the corresponding compositional information can be revealed. Using confocal Raman imaging, the distribution of lignin and cellulose in black spruce wood was investigated (Agarwal, 2006) and changes of molecular composition in secondary plant cell wall tissues of poplar wood were illustrated (Gierlinger and Schwanninger, 2006). Raman imaging of Arabidopsis thaliana, one of the most important model plants, was recently demonstrated (Schmidt et al., 2009). Principal component analysis (PCA) and partial least square (PLS) modeling can be incorporated in image analysis to provide a more detailed comparison of cell wall compositions at different mapped regions (Gierlinger et al., 2008b). Raman imaging technique was also used to compare lignification in wild type and lignin-reduced 4-coumarate-CoA ligase (4CL) transgenic Populus trichocarpa stem wood (Schmidt et al., 2009). Raman imaging was further implemented to provide a more complete picture of the effects of alkaline treatment on Miscanthus $x$ giganteus, a potential energy crop and a model lignocellulosic material. Longitudinal and transversal-section images of the parenchyma cells were generated, which revealed that lignin is removed preferentially from the inner surface of the cell wall and that cellulose is largely undisturbed (Chu et al., 2010).

Very recently our laboratory has developed a Raman imaging method to provide complete tissue/cell type specific compositional information for the first time (Sun et al., 2011). The 
method was demonstrated on stem sections of corn stover ranging from the epidermis to the pith area by both one-dimensional and two-dimensional chemical mapping. Lignin and cellulose abundance was determined in various cell types in the following order: sclerenchyma cells and tracheids $(\sim 5$ times $)>$ epidermal cells $(\sim 3$ times $)>$ bundle sheath cells > parenchyma cells. Unlike other Raman imaging work only showing the total lignin content, a Raman characterization study was performed to assign peaks for lignin compositions in terms of $p$-hydroxyphenyl, guaiacyl and syringyl units. Our imaging results have shown that significant amount of $p$-hydroxyphenyl units are present in the tracheids of corn stover stem, but not in the tracheids of the Eucalyptus globulus stem, which was corroborated by literature data (Galletti et al., 1996; Pinto et al., 2005).

Polarized Raman is another very useful tool for plant cell wall research by including polarizers in the optical path. Cao et al. (2006) has demonstrated a Raman study on the net orientation of biomacromolecules in the outer epidermal walls of mature wheat stems by comparing spectra collected with Raman light polarized perpendicular or parallel to the longitudinal axis of the cell. By changing the laser polarization direction in $3^{\circ}$ steps, Gierlinger et al. (2010) investigated the dependency between cellulose and laser orientation direction and determined cellulose microfibril angle in S1 and S2 layers of wood samples, which was validated by X-ray diffraction measurement.

A separate category of nonlinear Raman techniques represented by coherent anti-Stokes Raman scattering (CARS) microscopy and stimulated Raman scattering (SRS) microscopy have emerged in recent years for plant cell wall research. CARS is orders of magnitude more sensitive, much faster in image acquisition and less affected by fluorescence compared with spontaneous Raman microscopy, and has the intrinsic capability of three-dimensional sectioning due to the nonlinear nature. CARS imaging of lignin in cell walls was demonstrated using corn stover (Evans and Xie, 2008). However, a CARS spectrum is different from its corresponding spontaneous Raman spectrum due to a nonresonant background, which causes difficulties in image interpretation. The major advantages SRS offers include an identical response to spontaneous Raman scattering, a linear dependence on the analyte concentration and fast image acquisition. Saar et al. (2010) has realized realtime monitoring of delignification reaction in corn stover using the acid chlorite method by SRS with high spatiotemporal resolution. However, some major problems associated with nonlinear Raman techniques are the cost and limited access to the instruments that are not commercially available and system optimization requirement for daily usage, which allows only very experienced people to operate the instruments.

\section{Cell wall analysis by 2D and 3D electron microscopy}

Plant cell walls are highly complex networks made of carbohydrates, lignins and some proteins. Apart from the complexity of individual plant cell walls, the walls can be very diverse in composition and organization, between different groups of plants, between different species and even within same plant, organ, tissue and cell type. Cell walls are also dynamic in nature and their ultrastructure alters with growth and differentiation (Carpita and Gibeaut, 1993; Niklas, 2004; Popper, 2008; Sarkar et al., 2009). Molecular resolution imaging of plant cell walls is needed to obtain a detailed structural knowledge of cell wall organization, which in turn is needed for rational engineering of cell walls for improving biofuel production from biomass. Electron microscopy allows ultrastructural analysis at molecular resolution, whereas optical microscopy techniques are typically limited by the 
diffraction limit of the optical microscope and the signal-to-noise ratios encountered in autofluorescent specimens.

Transmission electron microscopy (TEM) allows an in-depth analysis of cellular ultrastructure and has been used to study plant cell walls since 1940s yielding the first highresolution ultrastructural insights (Preston et al., 1948). For TEM analysis samples need to be thin for the electron beam to penetrate (ideally $\sim 100-300 \mathrm{~nm}$ ) and must be examined a vacuum, resulting in the necessity for resin embedding, followed by ultrathin sectioning. The necessary chemical sample preparation steps employed in a typical conventional protocol results in limited preservation: chemical fixation, heavy metal postfixation and staining, as well as organic solvent dehydration, can lead to fixation staining and dehydration artifacts, such as the denaturation, aggregation and extraction of biological material as well as uneven or preferential staining. Moreover, even modern sample preparation protocols including specific staining techniques are predominantly optimized for cell membrane lipids, nucleic acids, and proteins, but not for carbohydrates and lignin. Some histochemical staining methods are used to stain cell wall components such as, (1) negative staining with uranyl acetate for cellulose; (2) PATCO (Periodic acid Thiocarbohydrazide - Silver Proteinate) method for hemicelluloses; (3) ruthenium red for pectins, (4) potassium permanganate for lignins (Krishnamurthy, 1999). However, these stains are often not highly specific and stain multiple cell wall components to various degrees. Distinguishing between cell wall components accurately at high resolutions is difficult by sole differential staining.

Most of the early high-resolution TEM imaging of plant cell walls was done on samples prepared by metal shadowing and surface replication after freeze-fracturing or freezeetching (Preston et al., 1948, McCann et al., 1990). While in principle no chemical fixatives, no dehydrating agents and no stains are used in this method, thus potentially retaining the samples closer to their native state, the images although potentially of high resolution are restricted to topological structural information in two-dimensions. Moreover, no chemical information can be obtained from this method as the imaging is done on the metal replica and not the biological sample. In recent years, sophisticated cryo-methods have been developed to minimize or completely overcome the limitations of conventional TEM sample preparation methods. Sophisticated cryo-methods such as high pressure freezing, followed by freeze-substitution and resin embedding typically display a superior quality of sample preservation in a much closer to native state (McDonald, 1999; McDonald \& MullerReichert, 2002, McDonald \& Auer 2006). High-pressure freezing followed by vitreous sectioning and cryo-TEM imaging offers preservation of biological samples closest to their native state (Al-Amoudi et al., 2004a, 2004b). These samples not only provide highresolution structural information, but can also provide chemical information by specific staining or by immunolabeling with target-specific gold-conjugated antibodies. Several monoclonal antibodies and carbohydrate-binding modules (CBM) are being developed against different cell wall components in many laboratories around the world (Knox, 2008; Pattathil et al., 2010), which can be used with TEM analysis to localize the various chemical components of plant cell walls with high precision. All TEM sample preparation methods mentioned above are usually time-consuming and labor intensive, although automatic microwave tissue processors are now commercially available for rapid chemical fixation, dehydration, resin embedding and polymerization.

Apart from sample preparation issues, conventional TEM imaging runs into a few other problems. Due to a small field of view in a TEM, only small representative areas of any 
sample can be imaged at a time. The sections used in TEM are also very thin (under a micron), which makes imaging larger cellular structures in their entirety an almost impossible task. Use of high-resolution wide-field imaging (montaging) and imaging serial sections can help in covering relatively larger sample areas. Aligning serial sections is specimen-dependant due to the characteristics of each section. Individual sections in a series may have differences in scaling and/or may have non-linear deformation because of sectioning, folding, drying, specimen tilt, and optical distortions of the microscope (Stevens and Trogadis, 1984). A more complicated limitation of conventional TEM is that the images obtained are 2D projections of a 3D volume, which means multiple molecular layers of the sample contribute to the same layer of the image. Such images can be difficult to interpret if the structures of interest are only a few nanometers in dimension and are very closely packed. Plant cell walls are a good example of this imaging problem. They are made up of a tightly packed network of cellulose microfibrils, each microfibril being $\sim 3 \mathrm{~nm}$ in diameter (Ohad \& Danon, 1964; Frey-Wyssling, 1968; Heyn, 1969; Somerville et al., 2004; Ding and Himmel, 2006). The cellulose microfibrils are tightly surrounded by hemicelluloses such as xyloglucans or arabinoxylans that form hydrogen bonds with the cellulose microfibrils and form cross-links between two neighboring cellulose microfibrils. The matrix space in between cellulose and hemicelluloses is crowded with complex nano-scale molecules of pectins and/or lignins (McCann et. al., 1990; Carpita and Gibeaut, 1993; Somerville et al., 2004). It is extremely challenging to resolve the ultrastructure of plant cell walls in situ by most imaging techniques available currently, including conventional TEM. Atomic force microscopy (AFM) has been successfully used to image plant cell wall ultrastructure at high resolutions (Ding and Himmel, 2006) but the information available is two-dimensional and only topological.

Electron tomography overcomes some of the limitations faced by conventional TEM and AFM. In this method, several hundred two-dimensional TEM images of the same sample are collected by rotation of the sample along the central axis in small increments, which leads to a 3D volume of data, which can be visualized, segmented out to develop realistic models and quantitatively analyzed in 3D. Individual layers within the 3D volume can be separately visualized and analyzed in different planes using sophisticated image analysis software. Different types of algorithms for automated segmentation are being developed, though the currently available algorithms are only reliable for relatively simple image sets. Since individual components of the plant cell walls are typically spaced close to the resolution limit of the data set, manual segmentation is still the most reliable method for analyzing plant cell wall tomograms. EM tomography data of plant cell walls can be used to measure dimensions, orientations and spacing of the different cell wall components. This method paired with biochemical analysis methods like Raman imaging and immunolabeling has the potential to develop precise, comprehensive 3D ultrastructural cell wall model(s) at molecular resolution.

EM tomography has been applied to study the 3D organization of the cellulose microfibrils in the S2 layer of the secondary cell wall in Pinus wood tissue (Xu et al., 2007, 2011), however the samples used in this study had been harshly chemically treated. Cryo electron tomography of vitrified sections of plant tissue can provide preservation closest to their native state. The processing of tomographic datasets (reconstruction, filtering and segmentation) of plant cell wall cryo-sections and faithful model development however, is highly challenging, as the images obtained by cryo-tomography are extremely low in contrast. Furthermore, since plant cell walls contain densely packed nano-scale components, 
cryo-tomography is not suitable for high-throughput imaging of plant cell walls. Instead high pressure freezing, followed by freeze-substitution and resin embedding is a way to go and will be the key to obtain high-throughput realistic cell wall models. EM tomography of high-pressure frozen, freeze-substituted, resin embedded samples has been used to study at unprecedented resolution the dramatic structural changes during cytokinesis and the assembly process of cell plates during the final stage of cell division, (Seguí-Simarro et al., 2008).

\section{Changes to biomass by acanning and transmission electron microscopy}

Apart from an in-depth look at the molecular ultrastructure of different plant cell walls, Scanning Electron Microscopy (SEM) can be utilized to swiftly characterize biomass samples from different pretreatment protocols and while 2D in nature provides a 3D impression of the effect such protocols had on plant cell walls. SEM uses backscattering properties of heavy atom-coated surfaces to determine surface topologies. SEM is strictly a surface technique, and while not yielding information about the inside of an object, it provides fast overviews of large areas at fairly high resolutions with relatively simple sample preparation, allowing rapid screening of many samples. Focused Ion Beam (FIB)/SEM is a promising new method that can provide continuous 3D information over a large depth range though it requires a much more sophisticated sample preparation as compared to conventional SEM and will be discussed further below.

Regarding sample preparation, usually, the best approach is to work with cross sections of plant stems (e.g. Arabidopsis or Brachopodium) that can be cut using a vibrating blade microtome (e.g. Leica VT1000S, Leica Microsystems), resulting in reproducible cross sections. In order to ensure reproducible results multiple sections of each stem are typically cut in water, picked up with a brush or a pair of very fine tweezers and placed on prepared SEM sample stubs. The sample can then be dehydrated and critical-point dried or directly mounted on sample stubs and sputter coated, which allows for better conductivity of the sample and therefore better SEM imaging results.

TEM with plant stem cross sections requires significantly more preparation than SEM (see section above), but yields more quantitative information regarding cell wall thickness and can discriminate between primary and secondary cell wall. We (Li et al. 2009, Çetinkol et al. 2010) have used the described SEM techniques to visualize the effects of different pretreatment techniques designed to break up plant parts before they can be subjected to either enzymes or microbes thus converting them into sugars and subsequently second or third generation biofuels. Both TEM and SEM were used (Yin et al. 2011) to visualize the isolation of plant organelles or changes of the plant structure due to mutations, affecting cell wall properties and susceptibility to deconstruction for second or third generation biofuels synthesis. Furthermore, SEM analysis can be used to study the fracture pattern in samples derived from the mechanical stress screening in order to determine whether the fracture pattern indicate ductile or brittle behavior.

\section{Examining microbial communities by advanced electron microscopy}

A variety of microbial communities are thought to have unique lignocellulolytic capabilities making them of great interest for the development of second and third generation biofuels. Among the natural degraders of lignocellulose are microbial communities that are found 
e.g. in the gut of wood-degrading insects such as termites, in ruminants, in compost or soil. Electron microscopy with its ability to conduct an analysis at a spatial resolution of about a nanometer allows the investigation of the interplay between the different bacterial cells that constitute a community, its association with the plant material as well as their macromolecular inventory and degradation strategies.

SEM can only be conducted on surfaces, e.g. plant part from the digestive system of a cellulose degrading animal containing the microbial community, or microbes filtered out of a microbial culture suspension. Since SEM imaging typically requires sample fixation, dehydration and critical point drying, followed by sputter coating, the fine details tend to get lost. The microscopy on those samples in a high-resolution SEM (typically, $2-10 \mathrm{kV}$ accelerating voltage are used) can visualize the shape of microorganisms, thus sometimes enabling an identification of certain species, and show both interaction between microbes and between microbes and the surface (e.g. plant material). It can thus be a valuable first insight into the composition and functioning of a microbial community, facilitated by the fact that the technique is rather quick and does not require extensive preparations. However, the technique does not enable a more detailed analysis of the microbial community and is limited to the surface of the samples, thus possibly representing only a small fraction of the sample that might not be typical for the sample in general.

If a more in-depth analysis of the microbial community is the goal, one has to use TEM instead of additional SEM. The analysis of a microbial community with TEM can visualize a lot of interesting traits in this community, including frequent cell-cell interactions, either directly or via a variety of microstructures such as pili and flagella. Even more interesting in this case are the interactions between microbial cells and the plant biomass, which is present in the sample. In studies of such communities (Knierim et al., in preparation) we have found different strategies of cell wall attachment and biomas digestion. An unresolved challenge is the direct identification of species in TEM or SEM. There have been recent advances in this field, combining TEM with Catalized Reporter Deposition Fluorescence In-Situ Hybridization (CARD-FISH), which can identify either groups of bacteria or even certain species (Knierim et al., submitted). However, this technique is extremely tedious and requires some compromises of the TEM imaging quality in order to enable the identification via CARD-FISH.

The described electron microscopy techniques are not only applicable to the understanding of microbial communities but can also be utilized for the analysis of bacteria that have been engineered for certain capabilities. Such capabilities that are developed by synthetic biologists can be the increased production of fuels, the production of different fuels (especially those with longer carbon chains which are more valuable than ethanol) or the assessment of toxicity of the produced biofuels. When combined with tag-based labeling TEM also allows a rational monitoring of protein expression levels, cell-to cell variation and subcellular localization. Thus the application of SEM and TEM to those samples can facilitate the re-engineering of microorganisms that are needed for the production of second and third generation biofuels.

A natural limitation of TEM usually is its coverage of very small sample volumes covered by thin sections. To overcome this problem, FIB/SEM can be employed, which provides a three dimensional view of large volumes of a microbial community at a resolution comparable to electron tomography. For FIB/SEM a similar sample preparation protocol as described above for TEM can be used, but one has to ensure a high internal contrast inside the plastic blocks. We have had very good experience with tannic acid for this purpose. During 
FIB/SEM imaging one must pay attention to the area of interest careful, as this technique is very time intensive and hence currently can only be applied to a limited number of volumes. Typically, volumes of $10 \times 10 \times 5 \mu \mathrm{m}$ can be covered at an estimated resolution around 10-15 $\mathrm{nm}$. The datasets that are produced this way easily get very large (in the several Gigabyte range) and require careful 3D reconstruction and analysis using software packages with those capabilities such as UCSF Chimera (http://www.cgl.ucsf.edu/chimera) or Amira (http://www.amira.com). We are currently drafting a manuscript on the FIB/SEM 3D analysis of the termite hindgut microbial community, where we classify and quantify constituent microbial community member according to size, shape and internal density characteristics, and map out their distribution with respect to the biomass (Knierim et al., in preparation).

An understanding of the functioning of microbial communities that are capable of lignocellulose degradation will ultimately lead to the development of better techniques for lignocellulose degradation in an industrial setting such as a biorefinery for second or third generation biofuels. We are still in the early steps of this understanding due to the high complexity and variability of these microbial communities, but if we can reduce the complexity by identifying a small set of microbes with valuable capabilities, we may be able to speed up this process. As the principles that are present in these microbial communities have been developed by evolution over billions of years, we can assume that they are very energy efficient, thus providing a maximal energy output while taking up a small amount of energy themselves - an important challenge for the design of industrial processes for the production of biofuels

\section{Outlook}

Improving feedstocks properties as well as optimizing each step of the deconstruction process and the fuels synthesis production step will decrease the production cost and is therefore key for replacing fossil fuels with biofuels. To accomplish such needed technological advances, one needs to resort to a variety of different biophysical techniques, typically carried out by specialists, that can quantify the effect of experimental intervention and lead to a detailed understanding of the physical, chemical and biological processes of lignocellulosic biofuel production.

\section{Acknowledgements}

This work was part of the DOE Joint BioEnergy Institute (http://www.jbei.org) supported by the U. S. Department of Energy, Office of Science, Office of Biological and Environmental Research, through contract DE-AC02-05CH11231 between Lawrence Berkeley National Laboratory and the U.S. Department of Energy. This work was in part supported in part by the Energy Biosciences Institute grant 007-G18.

\section{References}

Adapa P.K., Karunakaran C., Tabil L.G., and Schoenau G.J. 2009. Potential applications of infrared and raman spectromicroscopy for agricultural biomass. Agr Eng Inte: CIGR J11:1-25 
Agarwal U. 2006. Raman imaging to investigate ultrastructure and composition of plant cell walls: Distribution of lignin and cellulose in black spruce wood (Picea mariana) Planta 224:1141-1153

Agarwal U.P., and Ralph S.A. 1997. Ft-raman spectroscopy of wood: Identifying contributions of lignin and carbohydrate polymers in the spectrum of black spruce (Picea mariana). Appl Spectrosc 51:1648-1655

Akiyama K., Chikayama E., Yuasa H., Shimada Y., Tohge T., Shinozaki K., Hirai M.Y., Sakurai T., Kikuchi J., and Saito K. 2008. PRIMe: a Web site that assembles tools for metabolomics and transcriptomics. In Silico Biol 8: 339-345

Al-Amoudi A., Chang J., Leforestie A., McDowall A., Salamin L. M., Norlen L., Richter K., Blanc N. S., Studer D., and Dubochet, J. 2004. Cryo-electron microscopy of vitreous sections. EMBO J 23: 3583-3588

Al-Amoudi A., Norlen L., and Dubochet, J. 2004. Cryo-electron microscopy of vitreous sections of native biological cells and tissues. J Struct Biol 148: 131-135

Alves A., Schwanninger M., Pereira H., and Rodrigues J. 2006. Calibration of nir to assess lignin composition (h/g ratio) in maritime pine wood using analytical pyrolysis as the reference method. Holzforschung 60: 29-31

Atsumi S., Hanai T., and Liao, J.C. 2008. Non-fermentative pathways for synthesis of branched-chain higher alcohols as biofuels. Nature 451: 86-89

Baskin TI, Beemster GTS, Judy-March JE, Marga F. 2004. Disorganization of cortical microtubules stimulates tangential expansion and reduces the uniformity of cellulose microfibril alignment among cells in the root of arabidopsis. Plant Physiol 135(4):2279-2290.

Baucher M., Bernard-vailhé, M.A., Chabbert, B., Besle, J. M., Opsomer, C., Van Montagu M., and Botterman J. 1999. Down-regulation of cinnamyl alcohol dehydrogenase in transgenic alfalfa (Medicago sativa L.) and the effect on lignin composition and digestibility. Plant Mol Biol 39: 437-447

Bertran, M. S., and Dale B. E. 1986. Determination of cellulose accessibility by differential scanning calorimetry. J Appl Polymer Sci 32: 4241-4253

Boudet A. M., Goffner D., Marque C., Teulières C., and Grima-Pettenati J. 1998. Genetic manipulation of lignin profiles: a realistic challenge towards the qualitative improvement of plant biomass. Ag Biotech News Info 10: 295N-304N

Burk D. H., Liu B., Zhong R., Morrison W. H., and Ye Z. H. 2001. A katanin-like protein regulates normal cell wall biosynthesis and cell elongation. Plant Cell 13: 807-828

Cao Y., Shen D., Lu Y., and Huang Y. 2006. A raman-scattering study on the net orientation of biomacromolecules in the outer epidermal walls of mature wheat stems (Triticum aestivum). Ann Bot 97:1091-1094

Carpita N. C., and Gibeaut D. M. 1993. Structural models of primary cell walls in flowering plants: consistency of molecular structure with the physical properties of the walls during growth. Plant J 3: 1-30

Carr G. L. 1999. High-resolution microspectroscopy and sub-nanosecond time-resolved spectroscopy with the synchrotron infrared source. Vib Spectrosc 19: 53-60

Cavalier DM, Lerouxel O, Neumetzler L, Yamauchi K, Reinecke A, Freshour G, Zabotina OA, Hahn MG, Burgert I, Pauly M and others. 2008. Disrupting two arabidopsis 
thaliana xylosyltransferase genes results in plants deficient in xyloglucan, a major primary cell wall component. Plant Cell 20(6):1519-1537.

Çetinkol, Ö. P., Dibble D. C., Cheng G., Kent M. S., Knierim B., Auer M., Wemmer, D. E., Pelton J. G., Melnichenko Y.B., Ralph J., Simmons B. A. and Holmes, B. M. 2010. Understanding the impact of ionic liquid pretreatment on eucalyptus. Biofuels 1: 3346

Chen L., Carpita N. C., Reiter W. D., Wilson R. H., Jeffries C., and McCann M. C. 1998. A rapid method to screen for cell-wall mutants using discriminant analysis of fourier transform infrared spectra. Plant J 16: 385-392

Chen F., and Dixon R. A. 2007. Lignin modification improves fermentable sugar yields for biofuel production. Nature Biotech 25: 759-761

Chiang V. L., and Funaoka M. 1990. The difference between guaiacyl and guaiacyl-syringyl lignins in their responses to kraft delignification. Holzforschung 44: 309-313

Chu L. Q., Masyuko R., Sweedler J. V., and Bohn P. W. 2010. Base-induced delignification of Miscanthus $x$ giganteus studied by three-dimensional confocal raman imaging. Bioresour Technol 101:4919-4925

Coops H. and Van der Velde G. 1996. Effects of waves on helophyte stands: mechanical characteristics of stems of Phragmites australis and Scirpus lacustris. Aquatic Botany 53: $175-185$

Couchman P. R. 1981. The effect of degree of polymerization on glass-transition temperatures. Polym Eng Sci 21: 377-380

Czichos H., Saito T., and Smith L. 2006. Measurement methods for mechanical properties. In Materials measurement methods, Springer, 1: 283-387

Dai C. C., Tao J., Xie F., Dai Y., and Zhao M. 2007. Biodiesel generation from oleaginous yeast Rhodotorula glutinis with xylose assimilating capacity. African J Biotech 6: 21302134

Davison B. H., Drescher S. R., Tuskan G. A., Davis M. F., and Nghiem N. P. 2006. Variation of $S / G$ ratio and lignin content in a Populus family influences the release of xylose by dilute acid hydrolysis. Appl Biochem and Biotechnol 130: 427-435.

De Micco V, Aronne G. 2007. Combined histochemistry and autofluorescence for identifying lignin distribution in cell walls. Biotech Histochem 82(4):209-216.

D'Haeze W, Gao M, De Rycke R, Van Montagu M, Engler G, Holsters M. 2007. Roles for azorhizobial nod factors and surface polysaccharides in intercellular invasion and nodule penetration, respectively. Mol Plant Microbe Interact 11(10):999-1008.

Ding, S. and Himmel, M. E. 2006. The maize primary cell wall microfibril: A new model derived from direct visualization. J Agric Food Chem, 54: 597-606

Dokken K. M., Davis L. C. 2007. Infrared imaging of sunflower and maize root anatomy. J Agric Food Chem 55:10517-10530

Dokken K. M., Davis L. C., and Marinkovic N. S. 2005. Use of infrared microspectroscopy in plant growth and development. Appl Spectrosc Rev 40: 301 - 326

Ehara K., Takada D., and Saka S. 2005. GC-MS and IR spectroscopic analyses of the ligninderived products from softwood and hardwood treated in supercritical. J Wood Sci 51: 256-261. 
Emmel A., Mathias A. L., Wypych F., and Ramos L. P. 2003. Fractionation of Eucalyptus grandis chips by dilute acid-catalysed steam explosion. Bioresour Technol 86: 105115.

Evans C. L., and Xie X. S. 2008. Coherent anti-stokes raman scattering microscopy: Chemical imaging for biology and medicine. Annu Rev Anal Chem 1:883-909

Flynn J. H., and Wall L. A. 1966. A quick, direct method for the determination of activation energy from thermogravimetric data. J Polym Sci Part B: Polym phys 4: 323-328

Frey-Wyssling (1968) The ultrastructure of wood. Wood Sci Tech 2: 73-83

Fromm J, Rockel B, Lautner S, Windeisen E, Wanner G. 2003. Lignin distribution in wood cell walls determined by tem and backscattered sem techniques. J Struct Biol 143(1):77-84.

Galletti G. C., Bocchini P., Smacchia A. M., and Reeves J. B. 1996. Monitoring phenolic composition of maturing maize stover by high performance liquid chromatography and pyrolysis/gas chromatography/mass spectrometry. J Sci Food Agric 71:1-9

Galletti G. C., Reeves J. B., and Bocchini P. 1997. Analytical pyrolysis as a tool to determine chemical changes in maize stovers during growth. J anal and appl pyrolysis 39: 105114

Ghetti P., Ricca L., and Angelini L. 1996. Thermal analysis of biomass and corresponding pyrolysis products. Fuel 75: 565-573

Gierlinger N., Goswami L., Schmidt M., Burgert I., Coutand C., Rogge T., and Schwanninger M. 2008a. In situ ft-ir microscopic study on enzymatic treatment of poplar wood cross-sections. Biomacromolecules 9:2194-2201

Gierlinger N., Luss S., König C., Konnerth J., Eder M., and Fratzl P. 2010. Cellulose microfibril orientation of picea abies and its variability at the micron-level determined by raman imaging. J Exp Bot 61:587-595

Gierlinger N., Sapei L., and Paris O. 2008b. Insights into the chemical composition of Equisetum hyemale by high resolution raman imaging. Planta 227:969-980

Gierlinger N., and Schwanninger M. 2006. Chemical imaging of poplar wood cell walls by confocal raman microscopy. Plant Physiol 140:1246-1254

Gierlinger N., and Schwanninger M. 2007. The potential of raman microscopy and raman imaging in plant research. Spectrosc-Int J 21:69-89

Goddard T.D., Huang C.C., and Ferrin T.E. 2004 Visualizing density maps with UCSF Chimera, J. Struct Biol. 157: 281-287

Grethlein H. E., and Converse A. O. 1991. Common aspects of acid prehydrolysis and steam explosion for pretreating wood. Bioresour Technol 36: 77-82

Grünwald C, Ruel K, Kim YS, Schmitt U. 2002. On the cytochemistry of cell wall formation in poplar trees. Plant Biol 4(1):13-21.

Guo D., Chen F., Wheeler J., Winder J., Selman S., Peterson M., and Dixon R. A. 2001. Improvement of in-rumen digestibility of alfalfa forage by genetic manipulation of lignin O-methyltransferases. Transgenic Research 10: 457-464

Hall M., Bansal P., Lee J. H., Realff M. J., and Bommarius A. S. 2010. Cellulose crystallinity a key predictor of the enzymatic hydrolysis rate. FEBS Journal 277: 1571-1582 
Harley C. D. G., and Bertness M. D. 1996. Structural interdependence: An ecological consequence of morphological responses to crowding in marsh plants. Functional Ecology 10: 654-661

Heraud P., Caine S., Sanson G., Gleadow R., Wood B. R., and McNaughton D. 2007. Focal plane array infrared imaging: A new way to analyse leaf tissue. New Phytologist 173:216-225

Heyn, A. N. J.1969 The Elementary Fibril and Supermolecular Structure of Cellulose in Soft Wood Fiber. J. Ultra. Res. 26: 52-68

Himmel M. E., Ding S., Johnson D. K., Adney W. S., Nimlos M. R., Brady J. W., and Foust T. D. 2007. Biomass recalcitrance: Engineering plants and enzymes for biofuels production. Science 315: $804-807$

Himmelsbach D. S., and Akin D. E. 1998. Near-infrared fourier-transform raman spectroscopy of flax (Linum usitatissimum 1.) stems. J Agric Food Chem 46:991-998

$\mathrm{Hu}$ Y., Zhong R., Morrison W. H. III, and Ye Z. 2003. The Arabidopsis RHD3 gene is required for cell wall biosynthesis and actin organization. Planta 217: 912-921

Huyen T. L., Ramond C., Dheilly R.M., and Chabbert B. 2010. Effect of harvesting date on the composition and saccharification of Miscanthus $\mathrm{x}$ giganteus. Bioresour Technol 101: 8224-8231

Ibarra D., Chávez M. I., Rencoret J., Río J. C. D., Gutiérrez A., Romero J., Camarero S., Martínez M. J., Jiménez-Barbero J., and Martínez A. T. 2007. Lignin modification during eucalyptus globulus kraft pulping followed by totally chlorine-free bleaching: A two-dimensional nuclear magnetic resonance, fourier transform infrared, and pyrolysis-gas chromatography/mass spectrometry study. J Agric Food Chem 55: 3477-3490

Ibrahim M. N. M., and Pearce G. R. 1983. Effects of chemical treatments combined with high-pressure steaming on the chemical composition and in vitro digestibility of crop by-products. Agricultural Wastes 7: 235-250

Igathinathane C., Womac A. R., Sokhansanj S., and Narayan S. 2008. Knife grid size reduction to pre-process packed beds of high- and low-moisture switchgrass. Bioresour Technol 99: 2254-2264

Jackson L. A., Shadle G. L., Zhou R., Nakashima J., Chen F., and Dixon R. A. 2008. Improving saccharification efficiency of Alfalfa stems through modification of the terminal stages of monolignol biosynthesis. Bioenerg Res 1: 180-192

Jaffe M., Collins G., and Mencze J. 2006. The thermal analysis of fibers in the twenty first century: From textile, industrial and composite to nano, bio and multi-functional. Thermochim Acta 442: 95-99

Jung S., Foston M., Sullards M. C., and Ragauskas A. J. 2010. Surface characterization of dilute acid pretreated Populus deltoides by ToF-SIMS. Energy Fuels 24: 1347-1357

Kaloustian J., El-Moselhy T. F., and Portugal H. 2003. Chemical and thermal analysis of the biopolymers in thyme (Thymus vulgaris). Thermochim Acta 401: 77-86

Keppler B. D., and Showalter A. M. 2010. IRX14 and IRX14-LIKE, Two Glycosyl transferases involved in Glucuronoxylan biosynthesis and drought tolerance in Arabidopsis. Molecular Plant 1: 1-8 
Kim U., Eom S. H., and Wada M. 2010. Thermal decomposition of native cellulose: Influence on crystallite size. Polym Degrad Stab 95: 778-781

Knierim B, Lin M., Desai M, van Leer B., Goddard T.D., Hugenholtz P., McDonald K.L., Webb R.I., Auer M. (2011) Multiscale three-dimensional Organization of the Termite Hindgut Elucidated by FIB/SEM, in preparation

Knierim B, Luef B., Wilmes P., Webb R.I., Auer M., Comolli L.R., Banfield J.F. (2011) Correlative microscopy for phylogenetic and ultrastructural characterization of microbial communities, submitted to ISME J.

Knox J.P. 2008 Revealing the structural and functional diversity of plant cell walls. Curr Opin Plant Biol 11: 308-313

Krishnamurthy KV. 1999. Methods in cell wall cytochemistry. Boca Raton, FL: CRC Press. pp: $190-220$

Krongtaew C., Messner K., Ters T., and Fackler K. 2010a. Characterization of key parameters for biotechnological lignocellulose conversion assessed by ft-nir spectroscopy. Part i: Qualitative analysis of pretreated straw. BioResources 5: 2063-2080

Krongtaew C., Messner K., Ters T., and Fackler K. 2010b. Characterization of key parameters for biotechnological lignocellulose conversion assessed by ft-nir spectroscopy. Part ii: Quantitative analysis by partial least squares regression. BioResources 5: 20812096.

Kubo S., and Kadla J. F. 2005. Hydrogen Bonding in Lignin: A fourier transform infrared model compound study. Biomacromolecules 6: 2815-2821

Lee C., Teng Q., Huang W., Zhong R., and Ye Z. 2009. Down-regulation of PoGT47C expression in Poplar results in a reduced Glucuronoxylan content and an increased wood digestibility by cellulase. Plant Cell Physiol 50: 1075 -1089

Lee C., Teng Q., Huang W., Zhong R., and Ye Z. 2010. The Arabidopsis family GT43 Glycosyltransferases form two functionally nonredundant groups essential for the elongation of Glucuronoxylan backbone. Plant Physiol 153: 526-541

Li C., Knierim B., Manisseri C., Arora R., Scheller H. V., Auer M., Vogel K. P., Simmons B. A., and Singh S. 2010. Comparison of dilute acid and ionic liquid pretreatment of switchgrass: Biomass recalcitrance, delignification and enzymatic saccharification. Bioresour Technol 101: 4900-4906

Li Y., Qian Q., Zhou Y., Yan M., Sun L., Zhang M., Fu Z., Wang Y., Han B., Pang X., Chen M., and Li J. 2003. BRITTLE CULM1, which encodes a COBRA-Like protein, affects the mechanical properties of rice plants. Plant Cell 15: 2020-2031

Lin K. W., Ladisch M. R., Voloch M., Patterson J. A., and Noller C. H. 1985. Effect of pretreatments and fermentation on pore size in cellulosic materials. Biotechnol Bioeng 27: 1427-1433

Lu F., and Ralph J. 1997. DFRC method for lignin analysis. 1. New method for $\beta$-aryl ether cleavage: lignin model studies. J Agric Food Chem 45: 4655-4660

Lu F., and Ralph J. 1998. The DFRC method for lignin analysis. 2. Monomers from isolated lignins. J Agric Food Chem 46: 547-552

Lu F., and Ralph J. 1999. The DFRC method for lignin analysis. 7. Behavior of cinnamyl end groups. J Agric Food Chem 47: 1981-1987 
Lu F.C., and Ralph J. 1997. Derivatization followed by reductive cleavage (DFRC method), a new method for lignin analysis: Protocol for analysis of DFRC monomers. J Agric Food Chem 45: 2590-2592

Lu X., Vora H., and Khosla C. 2008. Overproduction of free fatty acids in E. coli: Implications for biodiesel production. Metabolic Eng 10: 333-339

Marita J. M., Ralph J., Hatfield R. D., and Chapple C. 1999. NMR characterization of lignins in Arabidopsis altered in the activity of ferulate 5-hydroxylase. Proceedings of the National Academy of Sciences of the United States of America 96: 12328 -12332

McCann M, Stacey N, Wilson R, and Roberts K. 1993. Orientation of macromolecules in the walls of elongating carrot cells. J Cell Sci 106:1347-1356

McCann, M.C., Wells, B. and Roberts, K. 1990. Direct visualization of cross-links in the primary plant cell wall. J Cell Sci 96 : 323-334

McDonald, K. 1999. High-pressure freezing for preservation of high resolution fine structure and antigenicity for immunolabeling. Electron Microscopy Methods and Protocols (ed. by N.Hajibagheri). Humana Press, Totowa, NJ. pp. 77-97.

McDonald Kent L, and Auer Manfred 2006. High-pressure freezing, cellular tomography, and structural cell biology. Biotechniques. 41:137-143

McDonald, K. and Müller-Reichert, T. (2002) Cryomethods for thin section electron microscopy. Meth. Enzymol. 351: 96-123

Mills T. Y., Sandoval N. R., and Gill R. T. 2009. Cellulosic hydrolysate toxicity and tolerance mechanisms in Escherichia coli. Biotechnol for Biofuels 2: 1-11

Mouille G., Robin S., Lecomte M., Pagant S., and Höfte H. 2003. Classification and identification of arabidopsis cell wall mutants using fourier-transform infrared (ftir) microspectroscopy. Plant J 35: 393-404

Niklas K. J. 2004. The cell walls that bind the tree of life. BioScience 54: 831-841

Nuopponen M., Willför S., Jääskeläinen A. S., Sundberg A., and Vuorinen T. 2004. A uv resonance raman (uvrr) spectroscopic study on the extractable compounds of scots pine (pinus sylvestris) wood: Part i: Lipophilic compounds. Spectrochim Acta A 60: 2953-2961

Ohad, I. and Danon, D. (1964) On the dimensions of cellulose microfibrils. J Cell Biol 22: 302305

Papatheofanous M. G., Billa E., Koullas D. P., Monties B., and Koukios E. G. 1995. Two-stage acid-catalyzed fractionation of lignocellulosic biomass in aqueous ethanol systems at low temperatures. Bioresour Technol 54: 305-310

Pattathil S., Avci U., Baldwin D., Swennes A. G., McGill J. A., Popper Z., Bootten T., Albert A., Davis R. H., Chennareddy C., Dong R., O'Shea B., Rossi R. Leoff C., Freshour G., Narra R., O'Neil M., York W. S. and Hahn M. G. 2010. A comprehensive toolkit of plant cell wall glycan-directed monoclonal antibodies. Plant Physiol 153: 514-525

Paul S. A., Oommen C., Joseph K., Mathew G., and Thomas S. 2010. The role of interface modification on thermal degradation and crystallization behavior of composites from commingled polypropylene fiber and banana fiber. Polym Compos 31: 11131123

Pecina R., Burtscher P., Bonn G., and Bobleter O. 1986. GC-MS and HPLC analyses of lignin degradation products in biomass hydrolyzates. Fresenius' J Anal Chem 325: 461-465 
Pena M. J., Zhong R., Zhou G., Richardson E. A., O'Neill M. A., Darvill A. G., York W. S., and Ye Z. 2007. Arabidopsis irregular xylem8 and irregular xylem9: Implications for the Complexity of Glucuronoxylan Biosynthesis. Plant Cell 19: 549-563

Peng J., Lu F., and Ralph J. 1998. The DFRC method for lignin analysis. 4. lignin dimers isolated from DFRC-degraded Loblolly Pine wood. J Agric Food Chem 46: 553-560

Persson S, Caffall KH, Freshour G, Hilley MT, Bauer S, Poindexter P, Hahn MG, Mohnen D, Somerville C. 2007a. The arabidopsis irregular xylem8 mutant is deficient in glucuronoxylan and homogalacturonan, which are essential for secondary cell wall integrity. Plant Cell 19(1):237-255.

Persson S, Paredez A, Carroll A, Palsdottir H, Doblin M, Poindexter P, Khitrov N, Auer M, Somerville CR. 2007b. Genetic evidence for three unique components in primary cell-wall cellulose synthase complexes in arabidopsis. Proc Natl Acad Sci USA 104(39):15566-15571.

Petterson E.F., Goddard T.D., Huang C.C., Couch G.S., Greenblatt D.M., Meng E.C. Ferrin T.E. 2004 UCSF Chimera - a visualization systems for exploratory research and analysis.

Pinto PC, Evtuguin DV, Neto CP. 2005. Effect of structural features of wood biopolymers on hardwood pulping and bleaching performance. Ind Eng Chem Res 44: 9777-9784

Popper Z. A. 2008. Evolution and diversity of green plant cell walls. Curr Opin Plant Biol 11: 286-292

Prat R., and Paresys G. 1989. Multiple use apparatus for cell wall extensibility and cell elongation studies. Plant Physiol Biochem 27: 955-962

Preston, R. D., Nicolai, E., Reed, R. and Millard, A. 1948. An electron microscope study of cellulose in the wall of Valonia ventricosa. Nature 162: 665-667

Ralph J. 2007. Perturbing ligninfication. In The Compromised Wood Workshop 2007, K. Entwistle, P.J. Harris and J. Walker, Eds., Wood Technology Research Centre, University of Canterbury, New Zealand, Canterbury, pp. 85-112

Ralph J., and Hatfield R. D. 1991. Pyrolysis-GC-MS charecterization of forage ,aterials. J Agric Food Chem 39: 1426-1437

Ralph J., and Lu F. 1998. The DFRC Method for Lignin Analysis. 6. A Simple Modification for identifying natural acetates on lignins. J Agric Food Chem 46: 4616-4619

Reh U., Kraepelin G., and Lamprecht I. 1987. Differential scanning calorimetry as a complementary tool in wood biodegradation studies. Thermochim Acta 119: 143-150

Reiter W., Chapple C., and Somerville C. R. 1993. Altered growth and cell walls in a fucosedeficient mutant of arabidosis. Science 261: 1032-1035

Ryden P., Sugimoto-Shirasu K., Smith A. C., Findlay K., Reiter W., and McCann M. C. 2003. Tensile properties of Arabidopsis cell walls depend on both a Xyloglucan crosslinked microfibrillar network and Rhamnogalacturonan II-Borate complexes. Plant Physiol 132: 1033-1040

Saar B. G., Zeng Y., Freudiger C. W., Liu Y. S., Himmel M. E., Xie X. S., Ding S. Y. 2010. Label-free, real-time monitoring of biomass processing with stimulated raman scattering microscopy. Angew Chem 122: 5608-5611. 
Saariaho A-M, Jääskeläinen A-S, Nuopponen M, Vuorinen T. 2003. Ultra violet resonance raman spectroscopy in lignin analysis: Determination of characteristic vibrations of p-hydroxyphenyl, guaiacyl, and syringyl lignin structures. Appl Spectrosc 57: 58-66

Sarkar P., Bosneaga E. and Auer M. 2009. Plant cell walls throughout evolution: towards a molecular understanding of their design principles. J Exp Bot 60: 3615-3635

Samuel R., Pu Y., Raman B., and Ragauskas A. J. 2010. Structural characterization and comparison of Switchgrass ball-milled lignin before and after dilute acid pretreatment. Appl Biochem Biotechnol 162: 62-74

Schmidt M., Schwartzberg A., Perera P., Weber-Bargioni A., Carroll A., Sarkar P., Bosneaga E., Urban J., Song J., Balakshin M., Capanema E. A., Auer, M., Adams P. D., Chiang V. L. and Schuck P. J. 2009. Label-free in situ imaging of lignification in the cell wall of low lignin transgenic populus trichocarpa. Planta 230: 589-597.

Schmidt M., Schwartzberg A. M., Carroll A., Chaibang A., Adams P. D., and Schuck PJ. 2010. Raman imaging of cell wall polymers in Arabidopsis thaliana. Biochem Biophys Res Commun 395: 521-523.

Seguí-Simarro, J.M., Otegui, M. S., Austin, J. R. and Staehelin, A. L. 2008. Plant cytokinesis Insights gained from electron tomography studies. In: Verma DPS, Hong Z (eds) Cell division control in plants. Springer, Berlin/Heidelberg, pp 251-287

Serapiglia M. J., Cameron K. D., Stipanovic A. J., and Smart L. B. 2008. High-resolution thermogravimetric analysis for rapid characterization of biomass composition and selection of shrub willow varieties. Appl Biochem Biotechnol 145: 3-11

Sewalt V. J. H., Glasser W. G., and Beauchemin K. A. 1997. Lignin impact on fiber degradation. 3. reversal of inhibition of enzymatic hydrolysis by chemical modification of lignin and by additives. J Agric Food Chem 45: 1823-1828

Shao S., Jin Z., Wen G., and Liyama K. 2009. Thermo characteristics of steam-exploded bamboo (Phyllostachys pubescens) lignin. Wood Sci Technol 43: 643-652

Singh S, Simmons BA, Vogel KP. 2009. Visualization of biomass solubilization and cellulose regeneration during ionic liquid pretreatment of switchgrass. Biotechnol Bioeng 104(1):68-75.

Smith E, Dent G. 2005. Modern raman spectroscopy: A practical approach. Chichester, England: John Wiley \& Sons Ltd.

Soares, S., Cammino G., and Levchick S. 1995. Comparative study of the thermal decomposition of pure cellulose and pulp paper. Polym Degrad Stab 49: 275-283

Somerville, C., Bauer, S., Brininstool, G., Facette, M., Hamann, T., Milne, J., Osborne, E., Paredez, A., Persson, S., Raab, T., Vorwerk, S., and Youngs, H. (2004) Toward a systems approach to understanding plant-cell walls. Science 306: 2206-2211

Stevens, J.K. and Trogadis, J. 1984. Computer-assisted reconstruction from serial electron micrographs: a tool for the systematic study of neuronal form and function. Advan Cell Neurobiol 5: 341-369

Stewart D, Wilson H. M., Hendra P. J., and Morrison I. M. 1995. Fourier-transform infrared and raman spectroscopic study of biochemical and chemical treatments of oak wood (Quercus rubra) and barley (Hordeum vulgare) straw. J Agric Food Chem 43: 2219-2225 
Sun L., and Simmons B. A, Singh S. 2011. Understanding tissue specific compositions of bioenergy feedstocks through hyperspectral raman imaging. Biotechnol Bioeng 108: 286-295

Tang, Y., Pingitore F., Mukhopadhyay A., Phan R., Hazen T. C., and Keasling J. D. 2007. Pathway confirmation and flux analysis of central metabolic pathways in desulfovibrio vulgaris hildenborough using gas chromatography-mass spectrometry and fourier transform-ion cyclotron resonance mass spectrometry. $J$ Bacteriol 189: 940-949

Tirumalai V, Agarwal U, Obst J. 1996. Heterogeneity of lignin concentration in cell corner middle lamella of white birch and black spruce. Wood Sci Technol 30(2):99-104.

Tsujiyama S., and Miyamori A. 2000. Assignment of DSC thermograms of wood and its components. Thermochim Acta 351: 177-181

Vailhé M. A. B., Besle J. M., Maillot M. P., Cornu A., Halpin C., and Knight M. 1998. Effect of down-regulation of cinnamyl alcohol dehydrogenase on cell wall composition and on degradability of tobacco stems. J Sci Food Agric 76: 505-514

Vinzant T., Ehrman C., Adney W., Thomas S., and Himmel M. 1997. Simultaneous saccharification and fermentation of pretreated hardwoods. Appl Biochem Biotechnol 62: 99-104

Wilkinson J.M., and Santillana R. G. 1978. Ensiled alkali-treated straw. I. Effect of level and type of alkali on the composition and digestibility in vitro of ensiled barley straw. Anim Feed Sci Technol 3: 117-132

Wilson RH, Smith AC, Kačuráková M, Saunders PK, Wellner N, Waldron KW. 2000. The mechanical properties and molecular dynamics of plant cell wall polysaccharides studied by fourier-transform infrared spectroscopy. Plant Physiol 124: 397-406

Ximenes E., Kim Y., Mosier N., Dien B., and Ladisch M. 2010. Inhibition of cellulases by phenols. Enzyme Microb Technol 46: 170-176

Ximenes E., Kim Y., Mosier N., Dien B., and Ladisch M. 2011. Deactivation of cellulases by phenols. Enzyme Microbl Technol 48: 54-60

Xu, P, Donaldson, L. A., Gergely, Z. R, and Staehelin, L. A. 2007. Dual-axis electron tomography: a new approach for investigating the spatial organization of wood cellulose microfibrils. Wood Sc and Tech 41: 101-116

Xu, P., Liu, H., Donaldson, L. A., and Zhang, Y. 2011. Mechanical performance and cellulose microfibrils in wood with high S2 microfibril angles. J Mater Sci 46: 534-540

Yin, L., Verhertbruggen Y., Oikawa A, Manisseri C, Knierim B, Prak L., Krüger Jensen J., Knox J.P., Auer M., Willats W.G.T. Scheller H. V. (2011). "The Cooperative Activities of CSLD2, CSLD3 and CSLD5 are Required for Normal Arabidopsis Development." Molecular Plant, in press.

Yu M., Womac A. R., Igathinathane C., Ayers P.D., and Buschermohle M.J. 2006. Switchgrass ultimate stresses at typical biomass conditions available for processing. Biomass Bioenergy 30: 214-219

Yu P, McKinnon JJ, Christensen CR, Christensen DA, Marinkovic NS, Miller LM. 2003. Chemical imaging of microstructures of plant tissues within cellular dimension using synchrotron infrared microspectroscopy. J Agric Food Chem 51: 6062-6067 
Zhong R., Taylor J. J., and Ye Z. H. 1997. Disruption of interfascicular fiber differentiation in an Arabidopsis mutant. Plant Cell 9: 2159-2170

Zhong R., Burk D. H., Morrison W. H., and Ye Z. 2002. A kinesin-like protein is essential for oriented deposition of cellulose microfibrils and cell wall strength. Plant Cell 14: 3101-3117

Zhong R., Burk D. H., Morrison W. H., and Ye Z. 2004. FRAGILE FIBER3, an Arabidopsis gene encoding a Type II Inositol Polyphosphate 5-Phosphatase, is required for secondary wall synthesis and Actin organization in fiber cells. Plant Cell 16: 32423259

Zhong R., Richardson E., and Ye Z. 2007. Two NAC domain transcription factors, SND1 and NST1, function redundantly in regulation of secondary wall synthesis in fibers of Arabidopsis. Planta 225: 1603-1611 


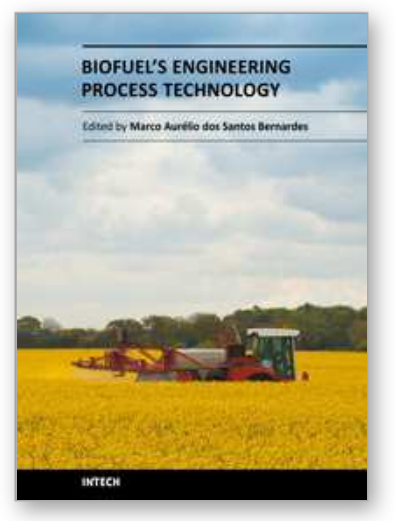

\author{
Biofuel's Engineering Process Technology \\ Edited by Dr. Marco Aurelio Dos Santos Bernardes
}

ISBN 978-953-307-480-1

Hard cover, 742 pages

Publisher InTech

Published online 01, August, 2011

Published in print edition August, 2011

This book aspires to be a comprehensive summary of current biofuels issues and thereby contribute to the understanding of this important topic. Readers will find themes including biofuels development efforts, their implications for the food industry, current and future biofuels crops, the successful Brazilian ethanol program, insights of the first, second, third and fourth biofuel generations, advanced biofuel production techniques, related waste treatment, emissions and environmental impacts, water consumption, produced allergens and toxins. Additionally, the biofuel policy discussion is expected to be continuing in the foreseeable future and the reading of the biofuels features dealt with in this book, are recommended for anyone interested in understanding this diverse and developing theme.

\title{
How to reference
}

In order to correctly reference this scholarly work, feel free to copy and paste the following:

Patanjali Varanasi, Lan Sun, Bernhard Knierim, Elena Bosneaga, Purbasha Sarkar, Seema Singh and Manfred Auer (2011). Quantifying Bio-Engineering: The Importance of Biophysics in Biofuel Research, Biofuel's Engineering Process Technology, Dr. Marco Aurelio Dos Santos Bernardes (Ed.), ISBN: 978-953-307-480-1, InTech, Available from: http://www.intechopen.com/books/biofuel-s-engineering-processtechnology/quantifying-bio-engineering-the-importance-of-biophysics-in-biofuel-research

\section{INTECH}

open science | open minds

\author{
InTech Europe \\ University Campus STeP Ri \\ Slavka Krautzeka 83/A \\ 51000 Rijeka, Croatia \\ Phone: +385 (51) 770447 \\ Fax: +385 (51) 686166 \\ www.intechopen.com
}

\author{
InTech China \\ Unit 405, Office Block, Hotel Equatorial Shanghai \\ No.65, Yan An Road (West), Shanghai, 200040, China \\ 中国上海市延安西路65号上海国际贵都大饭店办公楼405单元 \\ Phone: +86-21-62489820 \\ Fax: +86-21-62489821
}


(C) 2011 The Author(s). Licensee IntechOpen. This chapter is distributed under the terms of the Creative Commons Attribution-NonCommercialShareAlike-3.0 License, which permits use, distribution and reproduction for non-commercial purposes, provided the original is properly cited and derivative works building on this content are distributed under the same license. 